\title{
DESENVOLVIMENTO RURAL E PRONAF: um estudo para os municípios mineiros
}

\section{RURAL DEVELOPMENT AND PRONAF: a study for the Minas Gerais municipalities}

\author{
Fernanda Faria Silva \\ Doutora em Economia/ Professora do Departamento de Economia - UFOP) \\ fernfaria@gmail.com \\ Rodrigo Malta dos Santos \\ Mestre em Agronegócio pelo Programa de Pós Graduação em Agronegócio da Universidade de \\ Brasília (PROPAGA - UnB) \\ malta_555@hotmail.com
}

\section{Resumo}

A paisagem rural de Minas Gerais é bastante heterogênea e revela grandes desafios regionais. Por um lado, existem municípios com alto grau de desenvolvimento rural (como no Triângulo Mineiro, por exemplo), em contrapartida, muitos outros caracterizam-se pelo baixo grau de desenvolvimento rural, pobreza, elevada desigualdade social, desemprego, tal como se verifica no Vale do Jequitinhonha e Mucuri, cujas perspectivas de melhora dessas condições devem passar, entre outros fatores, pela ampliação do financiamento e investimento público. O objetivo desse trabalho é verificar a lógica da distribuição de recursos do PRONAF a partir de um Indicador de Desenvolvimento Rural (IDR). Baseado nos trabalhos de Kageyama (2004), Silva (2006) e Stege e Parré (2013) - foi feito um ranqueamento dos municípios de Minas Gerais nas dimensões Sócio Demográfica, Político Institucional, Econômica e Ambiental. A partir do IDR, pode-se comparar o grau de desenvolvimento rural dos municípios versus a liberação dos recursos do PRONAF. Foi corroborada a hipótese de que a lógica de concentração de recursos do PRONAF continua concentradora naqueles municípios com melhores indicadores econômicos, sociais, institucionais e ambientais. A despeito da criação de novas modalidades, como tentativa de incorporar outros públicos - alvos mais marginalizados, foi verificado que o programa continua tendo uma atuação mais efetiva nos municípios economicamente mais integrados.

Palavras - Chave: Indicador de Desenvolvimento Rural. PRONAF. Política Pública. Agricultura familiar. Minas Gerais.

\begin{abstract}
The rural landscape of Minas Gerais is very heterogeneous and reveals great regional challenges. On the one hand, there are municipalities with a high degree of rural development (for example in the 'Triângulo Mineiro'); otherwise, many of them presents characteristics such as low levels of rural development, poverty, high social
\end{abstract}


inequality and unemployment, such as in the Vale do Jequitinhonha and Mucuri, which perspectives for improvement of these conditions depends on the expansion of public finance and investments. The aim of this study is to test the target of PRONAF resources distribution by a Rural Development Indicator (IDR). Based on the works of Kageyama (2004); Silva (2006); Stege and PARRE (2013), a ranking of the municipalities of Minas Gerais was constructed contemplating several dimensions: Social, Demographic, Political, Institutional, Economic and Environmental. According to the IDR, it is possible to compare the level of rural development of the municipalities with the amount of resources received by PRONAF. The results was corroborated the hypothesis that the logic of concentration of PRONAF resources continues to be concentrated in those municipalities with better economic, social, institutional and environmental indicators. Despite the creation of new modalities as an attempt to incorporate more marginalized categories of familiar farm, it was verified that the program continues to have a more effective performance in the economically more integrated municipalities.

Keywords: Rural Development Index. PRONAF. Public Policy. Familiar Farm. Minas Gerais.

\section{INTRODUÇÃO}

Desde a conformação dos complexos agroindustriais, o setor agrícola brasileiro tem se diversificado e ampliado em termos de escala e organização, alterando a dinâmica econômica e social dos municípios que se beneficiam desta modernização. No entanto, este padrão de desenvolvimento não é uma realidade equânime no Brasil, tampouco para o estado de Minas Gerais. Como destaca Belik (2015), muito embora a heterogeneidade seja um fenômeno comum a todas as agriculturas, a desigualdade é uma marca da agricultura brasileira.

A agricultura mineira é bastante diversa, tanto em termos das suas características de conformação naturais e históricas, quanto nos diferentes tipos de organização da produção, tamanhos e formas de exploração, graus de integração com o mercado, produtividade e gestão da força de trabalho. Também, são bastante heterogêneos os impactos das ações das políticas públicas nos municípios caracteristicamente rurais e, também, os padrões de desigualdade no meio rural deste estado.

A década de 1990 foi marcada por um conjunto de transformações políticas, sociais e econômicas que possibilitam a consolidação da agricultura familiar no Brasil. De acordo com Schneider e Cassol (2013), as bases legais e institucionais criadas pela Constituição de 1988 possibilitaram que a sociedade civil pudesse participar mais 
ativamente das políticas públicas. A redefinição do Estado brasileiro introduziu a possibilidade de institucionalização de conselhos gestores de políticas setoriais, ponto no qual a agricultura familiar ganhou maior apoio ${ }^{1}$. Aliado à estabilidade macroeconômica advinda no pós Plano Real, as políticas mais descentralizadas de apoio aos pequenos agricultores se fortaleceram.

A partir da criação do Programa Nacional de Fortalecimento da Agricultura Familiar (PRONAF) em 1995, foi instalada uma política pública abrangente e voltada exclusivamente para os agricultores familiares. De acordo com Silva (2006), a partir dos documentos oficiais do Programa, seu propósito era fornecer crédito a baixo custo aos agricultores familiares, que até então não tinham nenhum programa específico de fomento à sua modalidade; bem como integrar grupos de agricultores menos estruturados às redes de negócios agropecuários, tentando conciliar estratégias de desenvolvimento sustentável da agricultura familiar e ampliação da capacidade produtiva, do número de empregos no campo e melhoraria na renda dos agricultores.

Fortalecidos pela aprovação do Projeto de Lei da Agricultura Familiar em 2006, pela qual foi instituída a Política Nacional de Agricultura Familiar e de Empreendimentos Familiares Rurais, os agricultores familiares passaram a ser reconhecidos como um segmento produtivo, o que contribui para a descentralização de ações referentes à sustentabilidade ambiental e socioeconômica, melhoria das condições e equidade na aplicação de políticas públicas e a participação de agricultores familiares na formulação e implementação dessas políticas.

Uma vez consolidado, o PRONAF ampliou o direcionamento de recursos financeiros por meio de modalidades específicas. Quase vinte anos após o início da sua implementação, o Programa passou por reestruturações, ampliando o seu escopo em termos dos enquadramentos de agricultores favorecidos por esta política pública. Por isso, este trabalho objetiva analisar a lógica da distribuição de recursos do PRONAF no estado de Minas Gerais, a partir da caracterização dos municípios beneficiados por tal política. Tal categorização será feita por meio um Indicador de Desenvolvimento Rural (IDR) adaptado dos trabalhos de Kageyama (2004), Silva (2006) e Stege e Parré (2013).

Para realizar esta investigação, o artigo foi estruturado em duas partes. A primeira delas tem um propósito de contextualização sobre a dinâmica recente do Programa em termos de sua magnitude e abrangência. Nesta parte do trabalho será 
analisada a evolução do PRONAF nos últimos vinte anos, no que tange ao volume de recursos e sua distribuição regional e contratos, destacando o caso de Minas Gerais.

A partir de então, foi feita a categorização do grau de desenvolvimento rural dos municípios mineiros a partir do Indicador de Desenvolvimento Rural (IDR), com o intuito de analisar o perfil dos municípios que tem recebido os recursos deste Programa. O propósito deste esforço é verificar se as localidades com maior grau de desenvolvimento rural (auferida pelo IDR) são, também, as municipalidades que mais recebem financiamentos do PRONAF.

Posteriormente, passam-se às principais conclusões do estudo em questão. Corroborando com parte dos estudos anteriores resgatados neste artigo, foi evidenciada a importância do Programa enquanto instrumento de política pública para o meio rural, no entanto, ainda fortemente concentrado nos municípios com maior grau de desenvolvimento rural, voltados para produtos com maior integração econômica.

\section{Distribuição regional de recursos do PRONAF e o caso de Minas Gerais}

Essa seção pretende oferecer um panorama geral da distribuição dos recursos do PRONAF atendo-se especificamente ao caso de Minas Gerais. A escolha deste estado para análise deve-se à heterogeneidade estrutural da sua agricultura: da predominância da agricultura patronal e altamente mecanizada de regiões como o Triângulo Mineiro, confrontando-se com o cenário oposto da agricultura de subsistência e relativamente pouco integrada típica de uma parte dos municípios do Vale do Jequitinhonha, ao nordeste do Estado.

O recorte temporal selecionado para esta análise encerra-se no ano de 2012 devido à indisponibilidade dos dados secundários por meio dos órgãos oficiais. Foi constatada uma grande lacuna de informações recentes referentes ao dispêndio de cada uma das 16 linhas de crédito do PRONAF o que dificulta uma análise mais profunda da efetividade do programa. Silveira e Valadares (2014) ainda citam outro problema: o fato de não mais se disponibilizar dados de contratos e do valor dos empréstimos de forma desagregada nem para as linhas de crédito, nem para os grupos de agricultores, ou para os municípios. Os mesmos autores afirmam que os dados desagregados apresentados pelo Ministério do Desenvolvimento Agrário (MDA) e que fomentaram diversos 
trabalhos sobre o PRONAF não estão mais disponíveis, devido às discrepâncias com os dados do Banco Central do Brasil (BACEN).

Dessa forma, é necessário ter bastante cautela ao fazer uma análise crítica do programa e assumir posições a partir dos dados apresentados neste trabalho, disponibilizados pelo MDA. Embora essa base de dados apresente informações em diferentes níveis regionais (Brasil, Grandes Regiões, Estados e Municípios), essas não podem ser desagregadas em termos das suas linhas de crédito, contratos ou enquadramentos que receberam os maiores montantes de recursos em termos municipais, por exemplo.

Como pode ser visto, os dados restringem-se ao total de contratos e o valor total financiado. Por isso, a distribuição dos recursos do PRONAF está organizada por grandes regiões, uma vez que o processo de concentração se reflete no aumento de participação dos agricultores mais consolidados e concentrados na Região Sul - e em empréstimos de custeio - o que reforça uma tendência já apresentada em trabalhos como Silva (2006), Corrêa e Silva (2007) e que é confirmada no gráfico 01.

Por outro lado, os agricultores menos integrados, do grupo B, se concentram na região Nordeste, e utilizam, primordialmente, empréstimos de investimento. Já a modalidade que se dirige aos assentados da Reforma Agraria vem se concentrando, cada vez mais, nas regiões Norte e Centro-Oeste (Silveira e Valadares, 2014, p. 5). O Gráfico 01 também apresenta a distribuição do volume de crédito ainda continua desigual. Mesmo em 2012, depois de passar por inúmeras reformulações, o PRONAF continua distribuindo cerca de $50 \%$ do valor total dos financiamentos para a Região Sul do país. Enquanto isso, Norte e Nordeste continuam recebendo pouco mais de $5 \%$ do valor total.

Por outro lado, como verificado, o número de contratos firmados pelo PRONAF aumentou muito, principalmente na Região Nordeste, o que também é representado no Gráfico 02. Nele, verifica-se que de 1999 a 2012, a participação do Nordeste em porcentagem aumentou de $24 \%$ para $45 \%$ do total de contratos do PRONAF. Por outro lado, as regiões Norte e Centro-Oeste, continuaram tendo pouca participação no total de contratos. 
Gráfico 01 - Percentual dos Financiamentos do PRONAF por Regiões, 1999 - 2012.

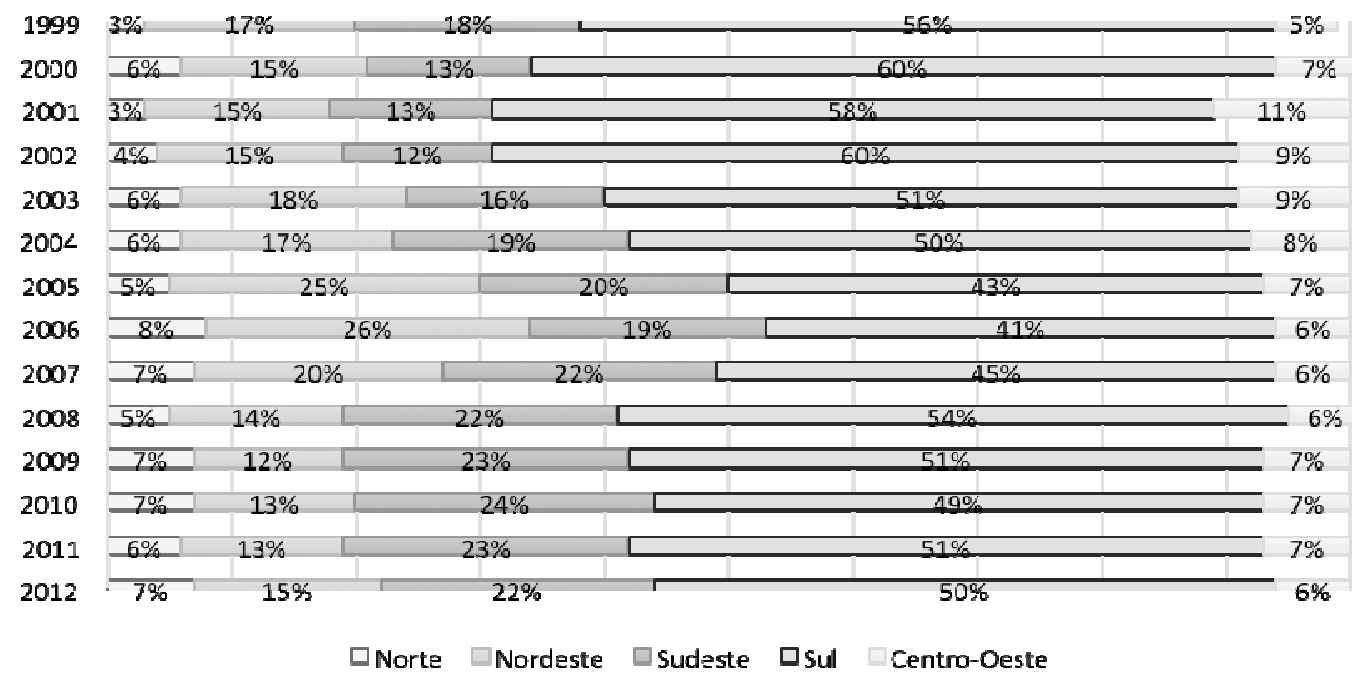

Fonte: Silveira e Valadares (2014) a partir dos dados do Banco Central do Brasil - Anuário Estatístico do Crédito Rural (1999 a 2012).

A região Sul, mesmo concentrando a maior parte do Valor Total dos Financiamentos deste Programa, teve uma queda sensível em termos de participação do número total de contratos (em 1999 a Região detinha 60\% dos contratos, em 2012 eram apenas 33\%). Reforçando este panorama regional da distribuição dos recursos, os gráficos 03 e 04 (em seguida) apresentam a distribuição regional do valor financiado por modalidade (PRONAF Investimento e PRONAF Custeio, respectivamente).

Gráfico 02 - Distribuição do Total de Contratos do PRONAF por Regiões, 1999 - 2012

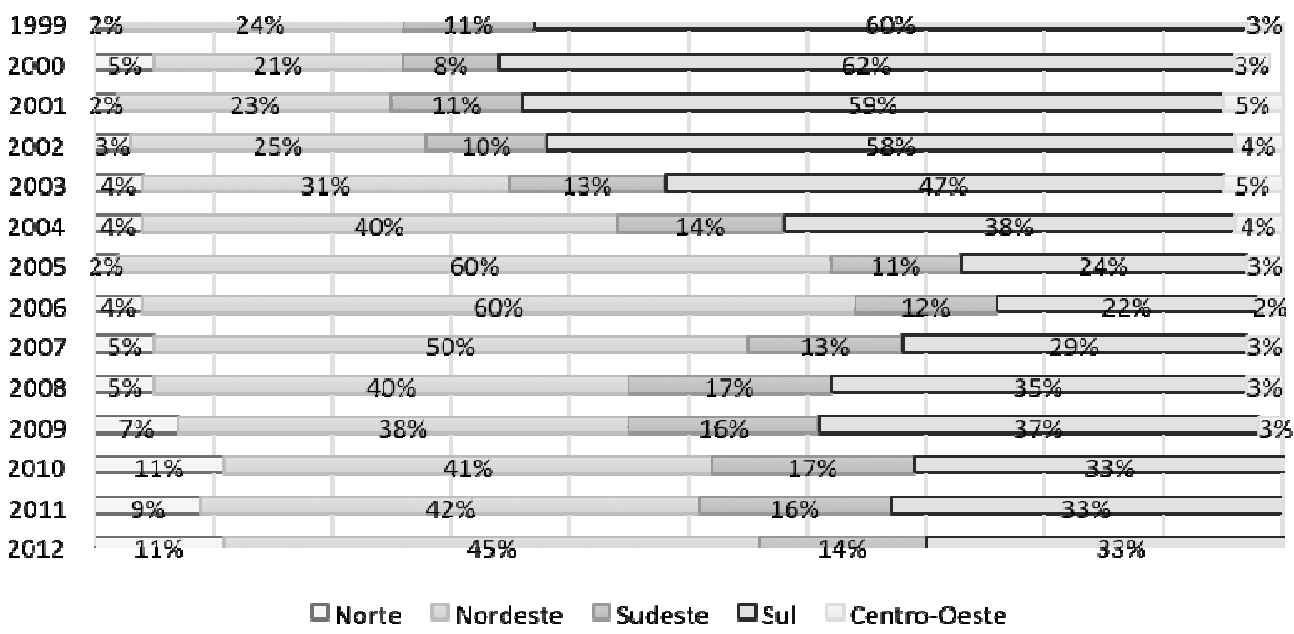

Fonte: Silveira e Valadares (2014) a partir dos dados do Banco Central do Brasil - Anuário Estatístico do Crédito Rural (1999 a 2012). 
No Gráfico 03 se pode observar que de 1999 a 2006, a região Sudeste aumentou sua participação no total financiado pelo PRONAF Investimento, contrabalanceando uma crescente perda de participação da região Sul nesse período. Da mesma forma, até o ano de 2006, o Nordeste aumentou gradativamente sua participação no valor total dos financiamentos na modalidade PRONAF Investimento. Contudo, de 2006 a 2012, verifica-se uma reconcentração do montante financiado nas regiões Sul e Sudeste (que em 2012 já ocupavam $60 \%$ do total).

No entanto, no Gráfico 04 (referente à distribuição regional de recursos do PRONAF Custeio), percebe-se uma concentração majoritária na Região Sul, que sempre se manteve de alguma forma estável na faixa de $60 \%$ do total. Neste gráfico, ressalta-se a baixa participação das regiões Norte e Nordeste. Fica claro que o PRONAF Custeio se dirige primordialmente para a região Sul, dado que $65 \%$ do valor financiado e $62 \%$ dos contratos referentes a essa modalidade tem como destino agricultores familiares dessa região.

Gráfico 03 - Distribuição dos Financiamentos de Investimento (PRONAF) 1999 2012.

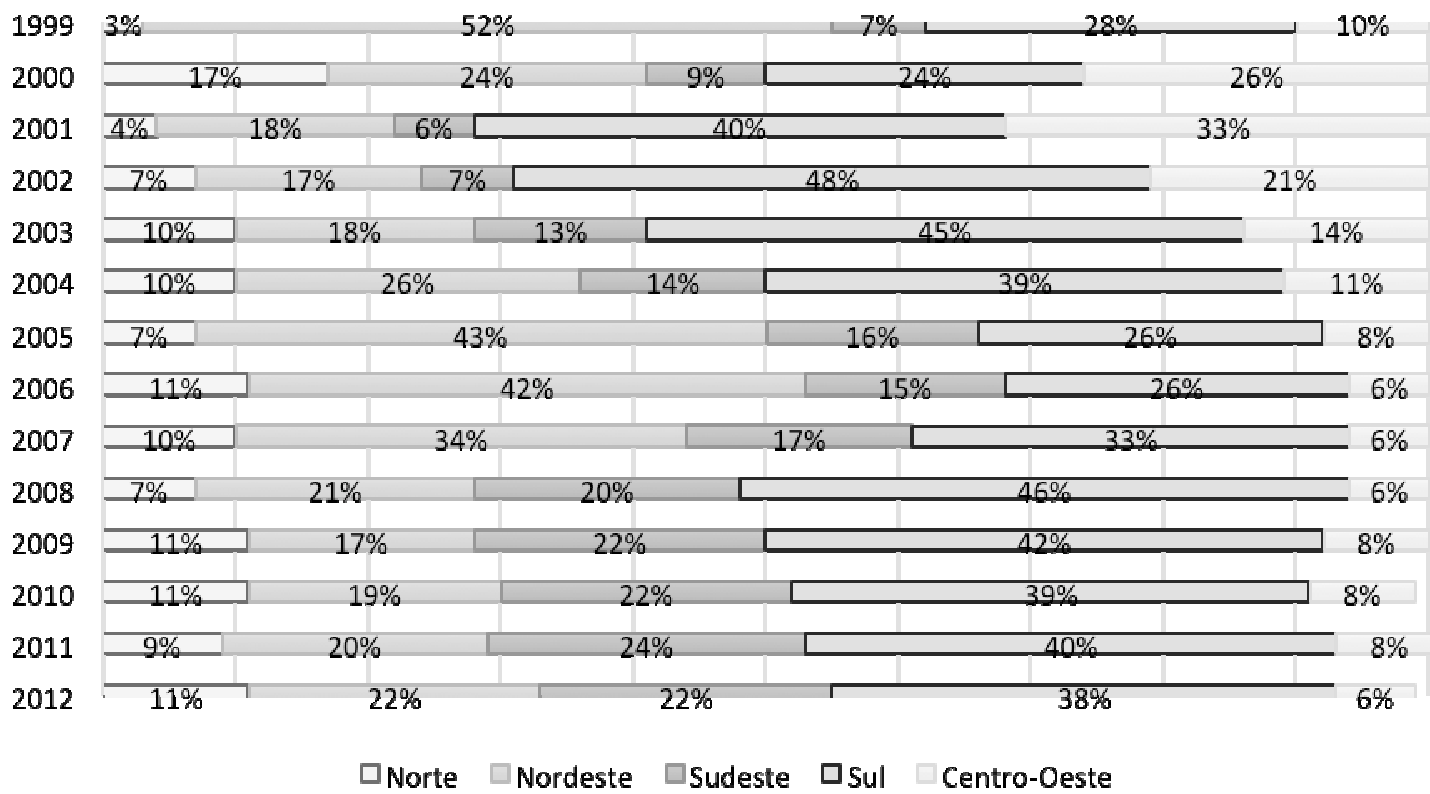

Fonte: Silveira e Valadares (2014) a partir dos dados do Banco Central do Brasil - Anuário Estatístico do Crédito Rural (1999 a 2012). 
Gráfico 04 - Percentual dos Financiamentos de Custeio (PRONAF) 1999 - 2012

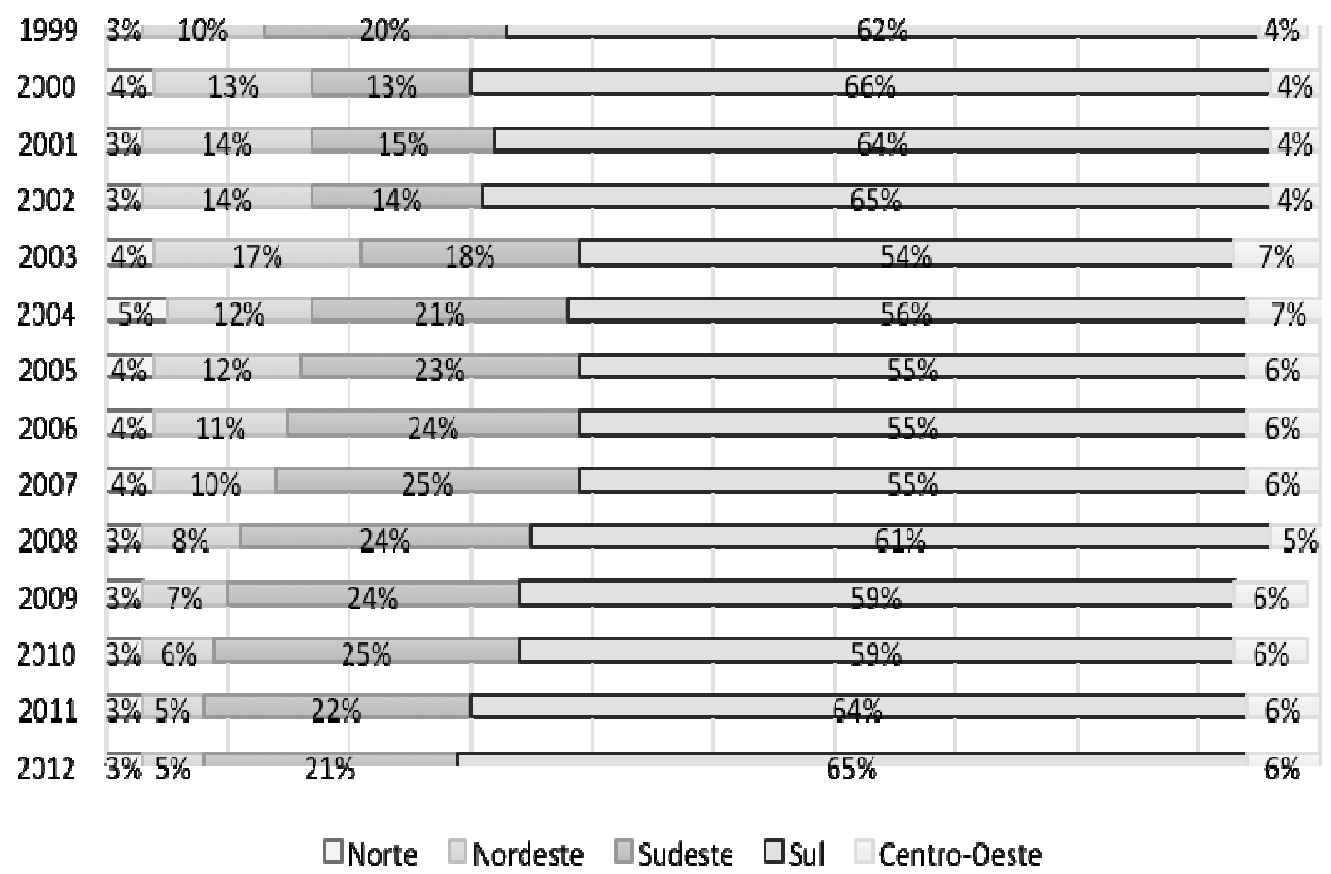

Fonte: Silveira e Valadares (2014) a partir dos dados do Banco Central do Brasil - Anuário Estatístico do Crédito Rural (1999 a 2012).

Embora tenha havido um aumento expressivo no número de contratos para os agricultores familiares nordestinos (representando $45 \%$ dos contratos do PRONAF no Brasil), a distribuição de crédito ainda se dá de forma desigual. Segundo o BACEN, de 2005 a 2012, o valor médio dos contratos cresceu, em números reais, 69\% na região Nordeste. Na região Sul, o valor médio dos contratos cresceu $85 \%$ em termos reais. Isso reforça o que diversos autores já relataram em seus trabalhos: o PRONAF concede, até os dias de hoje, crédito que atende a agricultura familiar como um todo, mas, os valores dos financiamentos ainda estão lastreados na capacidade de pagamento do pequeno agricultor, reforçando os argumentos de Silva (2006), Guanziroli (2007), Silveira e Valadares (2014).

Dessa forma, o PRONAF reforça a segmentação da agricultura familiar no Brasil ao financiar os agricultores seguindo uma lógica mercantil. Ao analisar os contratos fica nítida a segmentação regional do programa: o Nordeste, mesmo sendo a região com o maior número de contratos não recebe a maior parte do valor dos financiamentos, evidenciando o foco nas regiões Sul e Sudeste, que possuem agricultores familiares mais estruturados. 


\section{$O$ caso de Minas Gerais}

O estado de Minas Gerais possui uma estrutura fundiária bastante heterogênea sob o ponto de vista regional e das características das propriedades e agricultores, como visto no quadro 1. Tal heterogeneidade pode ser ilustrada pela presença de latifúndios do Triângulo Mineiro com uma agricultura de exportação bastante característica dos complexos agroindustriais vis à vis o alto percentual de pequenas propriedades do Vale do Jequitinhonha - estas últimas, que se assemelham às propriedades familiares do sertão nordestino.

Mesmo quando analisamos apenas as propriedades de agricultura familiar do Estado, não se pode estabelecer um padrão. Outro exemplo, na região sul do estado (na Serra da Mantiqueira) e na Zona da Mata predominam a agricultura familiar mais integrada ao mercado (às redes de comércio e de distribuição), enquanto isso, no Norte e Nordeste ainda existem muitas propriedades familiares voltadas à subsistência e que não estão integradas à economia.

Quadro 01 - Distribuição da Agricultura Familiar no Estado de Minas Gerais (2014)

\begin{tabular}{|c|c|c|}
\hline $\begin{array}{c}\text { Mesorregião Total de } \\
\text { Agricultores }\end{array}$ & $\begin{array}{c}\text { Total de Agricultores } \\
\text { Familiares }\end{array}$ & $\begin{array}{c}\text { Participação dos } \\
\text { Agricultores Familiares/ } \\
\text { Total de Agricultores do } \\
\text { Estado de MG (\%) }\end{array}$ \\
\hline Campo das Vertentes & 26.230 & $3,00 \%$ \\
\hline Central Mineira & 13.914 & $1,61 \%$ \\
\hline Jequitinhonha & 78.701 & $9,80 \%$ \\
\hline $\begin{array}{l}\text { Metropolitana de Belo } \\
\text { Horizonte } \\
\end{array}$ & 52.317 & $6,04 \%$ \\
\hline Noroeste de Minas & 23.278 & $2,69 \%$ \\
\hline Norte de Minas & 214.434 & $24,75 \%$ \\
\hline Oeste de Minas & 33.405 & $3,86 \%$ \\
\hline Sul/Sudoeste de Minas & 128.441 & $14,83 \%$ \\
\hline Triângulo/Alto Paranaíba & 52.782 & $6,09 \%$ \\
\hline Vale do Mucuri & 35.351 & $4,08 \%$ \\
\hline Vale do Rio Doce & 85.886 & $9,91 \%$ \\
\hline Zona da Mata & 121.594 & $14,04 \%$ \\
\hline MINAS GERAIS & 866.333 & $100,00 \%$ \\
\hline
\end{tabular}

Fonte: Elaboração própria a partir de dados do Governo do Estado de Minas Gerais (2014).

Nos gráficos 05 e 06 têm-se, respectivamente, os dados sobre o número total de contratos nas modalidades Custeio e Investimento e o valor total destes financiamentos para Minas Gerais. 
Gráfico 05 - Número total de Contratos do PRONAF em Minas Gerais, 1999 - 2012

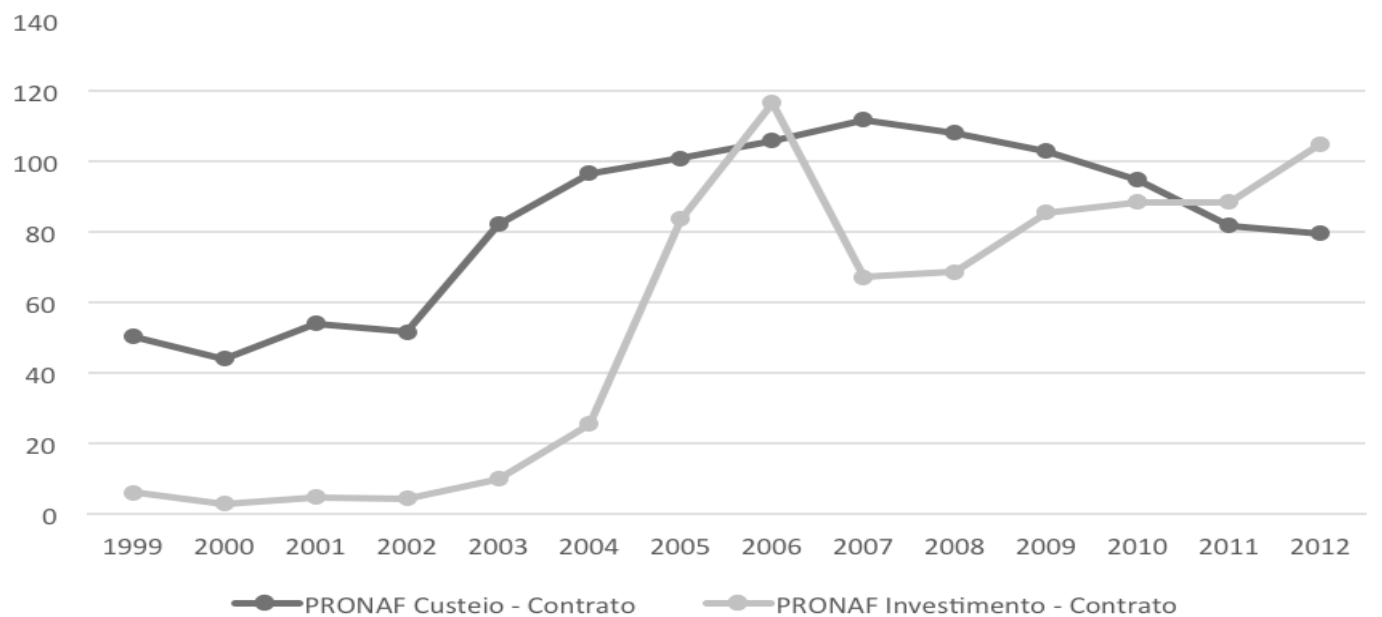

Fonte: elaboração própria a partir dos dados do Banco Central do Brasil - Anuário Estatístico do Crédito Rural (1999 a 2012).

Como podemos observar no Gráfico 05, de 2003 até o ano de 2006 o número de contratos assinados nas duas modalidades cresceu muito em Minas Gerais, em especial na modalidade PRONAF Investimento. Isso pode ser explicado pela criação de diversas modalidades dentro do PRONAF Investimento ao longo do primeiro mandato do Presidente Lula. Além disso, no período de 2003 a 2006 foram criados outros programas que auxiliaram a estruturação do PRONAF como o Programa de Aquisição de Alimentos (PAA) e o PRONAF Alimento que criaram uma alternativa para os pequenos produtores venderem seu excedente de produção.

Gráfico 06 - Valor total dos financiamentos de Custeio e Investimento do PRONAF em Minas Gerais, 1999 a 2012 - preços constantes de 2012- em R\$ 1000,00

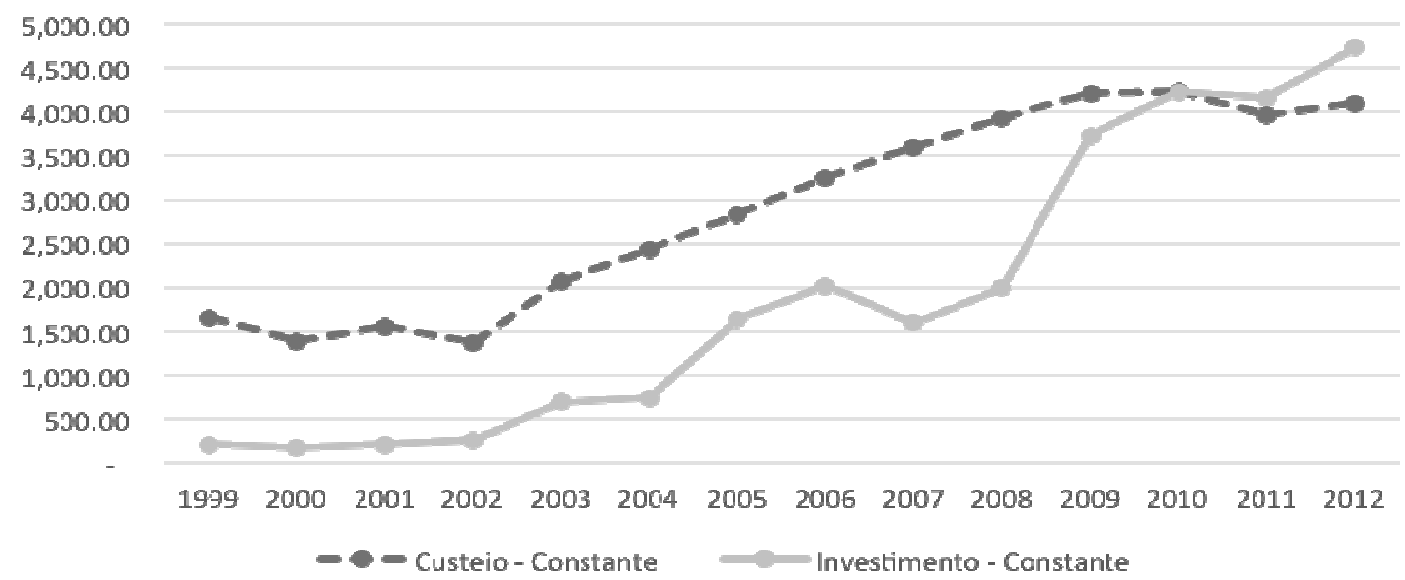

Fonte: elaboração própria a partir dos dados do Banco Central do Brasil - Anuário Estatístico do Crédito Rural (1999 a 2012). 
No entanto, como podemos ver no Gráfico 06, o aumento do número de contratos do PRONAF Investimento em Minas, não significou um aumento no valor total de financiamentos na mesma proporção. A modalidade PRONAF Investimento, voltada principalmente para a implantação de infraestrutura, só ultrapassa a modalidade de Custeio em 2011.

A modalidade PRONAF Custeio é descrita por diversos autores, dentre eles Silva (2006) e Silveira e Valadares (2014), como a que beneficia mais os pequenos agricultores que já estão inseridos no mercado e na agroindústria. Ou seja, essa modalidade não atinge, ou atinge superficialmente, os agricultores familiares que realmente necessitam de políticas públicas para se inserirem no mercado ou para saírem da zona de vulnerabilidade.

De acordo com Silveira e Valadares (2014, p. 9), não há evidências de que os agricultores familiares do Centro-Sul altamente associados às cadeias agroindustriais ou ao comércio exterior de commodities tenham sérias restrições de crédito, o que questiona os custos do PRONAF, se seu objetivo é superar as restrições de crédito dos agricultores familiares. Dessa forma, é questionável a eficácia de um programa voltado para a Agricultura Familiar quando este financia majoritariamente (tanto em nível nacional, quanto no estado de Minas Gerais) as propriedades que já estão inseridas na rede de negócios agropecuários. Por isso é louvável que a modalidade PRONAF Investimento, por meio de suas novas modalidades ${ }^{2}$, tenha ganhado mais espaço nos últimos anos.

Com este esforço exploratório, procurou-se apresentar a dinâmica do Programa e algumas discrepâncias na concentração dos financiamentos, que revelam o quanto o PRONAF ainda se concentra em localidades economicamente mais desenvolvidas. $\mathrm{O}$ caso de Minas Gerais reflete o caso brasileiro em ambos os sentidos: dada a heterogeneidade da estrutura agrícola e, também, nas distorções quanto ao financiamento dos recursos. Até o ano de 2011 predominaram no estado os financiamentos do tipo Custeio, voltado para financiar atividades agropecuárias já consolidadas. Foi visto que os recursos são regionalmente concentrados naquelas mais dinâmicas economicamente (como o Sul e Sudeste brasileiro, conforme os gráficos 01,02 e 03 ilustraram). 
Para depurar tal constatação, na próxima seção será apresentado um indicador composto de desenvolvimento rural (IDR) para municípios de Minas Gerais com metodologia semelhante à usada por Kageyama (2004) e Silva (2006). Por meio de diferentes sub-indicadores formados a partir de dados que captam as dimensões econômicas, populacionais e de bem-estar social, o IDR será usado para averiguar, seguindo o argumento de (Silva, 2006), se o PRONAF continua atrelado à lógica concentradora de recursos em municípios com maior grau de desenvolvimento rural e cuja lógica de liberação via sistema bancário privilegia.

\section{Proposta de um indicador de desenvolvimento rural e a distribuição dos recursos do PRONAF em Minas Gerais}

Após a contextualização da dinâmica do PRONAF, feita na seção anterior, partese para uma categorização sobre o grau de desenvolvimento rural dos municípios mineiros para, em seguida, confrontar com a distribuição de recursos do Programa. O intuito é de verificar se permanece a mesma lógica concentradora de recursos naqueles municípios economicamente mais favorecidos, mesmo após ter sido evidenciada uma ampliação nos valores destinados e nas modalidades do Programa. Tal premissa segue os trabalhos de Silva (2006) e Corrêa \& Silva (2007) que constataram tal distorção.

Para este estudo, esta seção divide-se em três partes. Na primeira, serão apresentados os dados, as suas fontes, e a elaboração do Indicador de Desenvolvimento Rural (IDR). Na segunda seção será proposta uma categorização de desenvolvimento rural para os municípios mineiros. Na terceira parte será analisada a distribuição dos recursos do PRONAF pelos diferentes municípios de Minas Gerais contrapondo estes valores com o seu enquadramento sob o ponto de vista econômico, social, institucional e ambiental.

\section{Uma proposta de atualização do Indicador de Desenvolvimento Rural (IDR)}

Os indicadores sociais são importantes instrumentos para a averiguação e análise de políticas públicas. O objetivo desta parte do trabalho é explicar a origem dos dados, a metodologia aplicada à formação do indicador e a aplicabilidade do IDR enquanto instrumento de análise para ajudar no monitoramento e na aferição de políticas públicas 
voltadas para o meio rural. Será considerado o caso de Minas Gerais devido ao grande número de municípios $(853)^{3}$, bastante heterogêneos entre si. De acordo com os dados da EMATER -MG, sistematizados pelo Governo de Minas Gerais (2014, pg-23), o Norte de Minas Gerais e Vale do Jequitinhonha juntos perfazem 34,55\% do total de agricultores familiares mineiros, seguido pelo Sul/ Sudoeste de Minas, cuja participação se aproxima de $15 \%$.

O IDR foi baseado em conceitos semelhantes ao do Indicador de Kageyama (2004) e Silva (2006), com adaptações propostas por Araújo (2014) e Stege e Parré (2013). Ele permitirá classificar os municípios mineiros em quatro diferentes níveis de desenvolvimento rural: alto, moderado, baixo e muito baixo.

De acordo com Kageyama (2004) um Indicador de Desenvolvimento Rural deve ser capaz de refletir diferentes aspectos, no entanto, é difícil desenvolver um indicador que consiga abranger todas as questões desse ramo. Por isso o IDR deve ser entendido apenas como uma ilustração da realidade, que é muito mais complexa. Araújo (2014) enfatiza que, ao se elaborar um indicador composto, assume-se o risco de deixar de considerar possíveis variáveis relevantes "seja pela dificuldade de dados que a expressem, seja pela sua não identificação" (Idem, 2014, p. 50). O IDR é um indicador composto feito a partir da média de outros quatro indicadores, descritos no Quadro 02.

O primeiro indicador - ISD - procura medir questões sociais e demográficas dos municípios mineiros. Ao analisarmos o Indicador Sócio Demográfico pudemos observar que as cidades que obtiveram os mais altos níveis no ISD foram aquelas que apresentaram maiores taxas de coleta de lixo e redes de esgoto bem implantadas e estão aliadas à uma alta porcentagem de população rural e à quantidade de pessoas ocupadas no campo. Conforme apresentado, os dados do ISD foram obtidos no banco de dados do Datasus, a partir dos Censos do IBGE: Agropecuário (2006) e Demográfico (2010).

$\mathrm{O}$ segundo indicador visa captar alguma sensibilidade em termos do desenvolvimento institucional dos municípios mineiros. O Indicador Político Institucional (IPI) busca avaliar a participação da população nas eleições de 2010 e também aspectos ligados à educação da população. A maior participação da população nas eleições somada a uma alta taxa de alfabetização e expectativa de anos de estudo contribuem para um maior IPI e, consequentemente, contribuiria para um maior IDR. Conforme apresentado, os dados do Indicador Político Institucional foram fornecidos 
pelo TSE (2015) e pela plataforma virtual do Atlas do Desenvolvimento Humano no

Brasil (2013).

Quadro 02 - Indicadores selecionados para a caracterização dos municípios - Índice de Desenvolvimento Rural (IDR)

\begin{tabular}{|c|c|c|c|}
\hline Indicador & Variáveis & Cálculo & Fonte \\
\hline \multirow{4}{*}{$\begin{array}{c}\text { Sócio Demográfico } \\
\text { ISD = } \\
(\mathrm{X} 1+\mathrm{X} 2+\mathrm{X} 3+\mathrm{X} 4) / 4\end{array}$} & $\mathrm{X} 1$ & $\begin{array}{l}\text { Proporção dos domicílios que } \\
\text { possuem sistema de esgoto, rede } \\
\text { pública geral. }\end{array}$ & Datasus (2015) \\
\hline & $\mathrm{X} 2$ & $\begin{array}{l}\text { Proporção dos domicílios que } \\
\text { possuem lixo coletado por serviço, } \\
\text { empresa pública ou particular. }\end{array}$ & Datasus (2015) \\
\hline & $\mathrm{X} 3$ & $\begin{array}{l}\text { População rural / População Total do } \\
\text { Município }\end{array}$ & $\begin{array}{l}\text { IBGE - Censo } \\
\text { Demográfico } \\
(2010)\end{array}$ \\
\hline & $\mathrm{X} 4$ & $\begin{array}{l}\text { Pessoal ocupado em estabelecimentos } \\
\text { agropecuários em } 31 / 12 \text { (Pessoas). }\end{array}$ & $\begin{array}{c}\text { IBGE - Censo } \\
\text { Agropecuário (2006) }\end{array}$ \\
\hline \multirow{3}{*}{$\begin{array}{c}\text { Político Institucional } \\
\text { IPI }= \\
(\mathrm{X} 5+\mathrm{X} 6+\mathrm{X} 7) / 3\end{array}$} & $\mathrm{X} 5$ & $\begin{array}{l}\text { Comparecimento nas eleições no } 1^{\circ} \\
\text { turno em relação ao número total de } \\
\text { eleitores cadastrados. }\end{array}$ & TSE (2015) \\
\hline & X6 & $\begin{array}{l}\text { Taxa de alfabetização - maiores de } 15 \\
\text { anos. }\end{array}$ & $\begin{array}{c}\text { Atlas do } \\
\text { Desenvolvimento } \\
\text { Humano no Brasil } \\
(2013) \\
\end{array}$ \\
\hline & $\mathrm{X} 7$ & Expectativa de anos de estudo. & $\begin{array}{c}\frac{\text { Atlas do }}{\text { Desenvolvimento }} \\
\frac{\text { Humano no Brasil }}{(2013)}\end{array}$ \\
\hline \multirow{4}{*}{$\begin{array}{c}\text { Econômico } \\
\mathrm{IPE}= \\
(\mathrm{X} 8+\mathrm{X} 9+\mathrm{X} 10+\mathrm{X} 11) / 4\end{array}$} & $\mathrm{X} 8$ & $\begin{array}{l}\text { Proporção de pessoas com baixa renda } \\
\text { - Minas Gerais* }\end{array}$ & Datasus (2015) \\
\hline & $\mathrm{X} 9$ & $\begin{array}{l}\text { Valor do PIB Agropecuário / } \\
\text { Valor do PIB do município } \\
\end{array}$ & IPEADATA (2015) \\
\hline & $\mathrm{X} 10$ & $\begin{array}{l}\text { Pessoas ocupadas (10 anos ou mais) } \\
\text { nos domicílios rurais/ Total de } \\
\text { Pessoas ocupadas do município }\end{array}$ & $\begin{array}{c}\text { IBGE - Censo } \\
\text { Demográfico }(2010)\end{array}$ \\
\hline & $\mathrm{X} 11$ & $\begin{array}{l}\text { PIB per capita rural/ PIB per capita do } \\
\text { município }\end{array}$ & IPEADATA (2015) \\
\hline \multirow{3}{*}{$\begin{array}{c}\text { Ambiental } \\
\mathrm{IA}= \\
(\mathrm{X} 12+\mathrm{X} 13+\mathrm{X} 14) / 3\end{array}$} & $\mathrm{X} 12$ & $\begin{array}{l}\text { Número de estabelecimentos } \\
\text { agropecuários que adotam prática de } \\
\text { conservação do solo** / Número total } \\
\text { de estabelecimentos agropecuários }\end{array}$ & $\begin{array}{l}\text { IBGE - Censo } \\
\text { Agropecuário } \\
\quad(2006)\end{array}$ \\
\hline & $\mathrm{X} 13$ & $\begin{array}{l}\text { Número de Estabelecimentos } \\
\text { agropecuários da agricultura familiar/ } \\
\text { Número total de estabelecimentos } \\
\text { agropecuários }\end{array}$ & $\begin{array}{l}\text { IBGE - Censo } \\
\text { Agropecuário } \\
\quad(2006)\end{array}$ \\
\hline & $\mathrm{X} 14$ & $\begin{array}{l}\text { Número de Estabelecimentos que } \\
\text { fazem uso de agricultura orgânica/ } \\
\text { Número total de estabelecimentos } \\
\text { agropecuários }\end{array}$ & $\begin{array}{l}\text { IBGE - Censo } \\
\text { Agropecuário } \\
\quad(2006)\end{array}$ \\
\hline \multicolumn{4}{|c|}{$\frac{\mathrm{IDR}=\mathrm{ISD}+\mathrm{IPI}+\mathrm{IE}+\mathrm{IA}}{4}$} \\
\hline
\end{tabular}

Nota: * Os dados disponíveis são oriundos dos Censos Demográficos realizados em 1991, 2000 e 2010. Os dados foram processados pelo Instituto de Pesquisas Econômicas e Aplicadas - IPEA, de acordo com os critérios do indicador de Proporção de pessoas com baixa renda - B.5.1, dos Indicadores e Dados Básicos da Rede Interagencial de Informações para a Saúde - Ripsa. ** Consideramos a variável "Proteção e conservação de encostas (IBGE - Censo Agropecuário)" como proxy para a variável 
"Número de estabelecimentos agropecuários que adotam prática de conservação do solo" por ser a prática mais recorrente nas propriedades rurais de Minas Gerais.

Fonte: Tabulação própria, adaptado a partir dos trabalhos de Kageyama (2004); Silva (2006), Araújo (2014) e Stege e Parré (2013). Dados do Censo Demográfico (2010); Censo Agropecuário (2006); IPEADATA (2015); Ministério da Saúde - Datasus (2015); TSE (2015); Atlas de Desenvolvimento Humano (2013).

O terceiro grupo de variáveis compõe o Indicador Econômico (IE) e busca avaliar, de uma forma geral, o quão importante é a agricultura para a economia local ${ }^{4}$. Para isso, foi avaliado o peso do PIB Agropecuário municipal em relação ao PIB municipal. Também faz parte do indicador a porcentagem de pessoas ocupadas no campo em relação ao total de pessoas ocupadas em toda a municipalidade. Além disso, compõe o IE a proporção de pessoas de baixa renda na localidade. Os dados foram coletados junto ao IPEA, Datasus (2015) e IBGE (2010) por meio de consulta virtual aos sites institucionais. Ressalta-se a dificuldade de mensurar os rendimentos não monetários das propriedades, principalmente nos grupos de agricultores do tipo familiar. Dessa forma, ressalta-se que esses rendimentos não foram incorporados a este indicador.

Por fim, o Indicador Ambiental avalia práticas sustentáveis na agricultura, como a conservação dos solos e a utilização de técnicas não agressivas ao meio ambiente. A ideia é que os municípios com grande incidência de agricultores familiares contam com bons indicadores deste tipo (Kageyama, 2004). De acordo com Olivette et al. (apud Araújo, 2014), em estudo realizado no Estado de São Paulo foi mostrado que a presença de atividades relacionadas às monoculturas contribui para um maior uso de produtos químicos como defensivos, adubos e outros. Estas propriedades são grandes consumidoras de agrotóxicos, contribuindo para a poluição do ar, rios e/ou empobrecendo o solo. Por sua vez, as atividades praticadas pela agricultura familiar tendem a ser mais diversificadas, o que indicaria uma utilização mais restrita de técnicas que agridam o meio ambiente, além de menor presença de atividades monoculturas. Por conseguinte, quanto maior for o indicador ambiental, maior tende a ser a adoção de práticas de conservação do solo.

Também compõe esse indicador o quociente do número de propriedades da agricultura familiar em relação a propriedades não familiares. Este indicador é relevante para o âmbito ambiental, porque quanto maior o número de propriedades que fazem uso da agricultura orgânica e/ou têm práticas de conservação do solo no município, maior 
será o IA. Da mesma forma, um grande número relativo de propriedades caracterizadas como de agricultura familiar contribui para um maior IA. O Indicador Ambiental possui dados oriundos exclusivamente do Censo Agropecuário de 2006 realizado pelo IBGE. Uma vez tendo sido somados esses quatro "sub-indicadores", foi calculada a média simples, chegando ao resultado final do Indicador de Desenvolvimento Rural:

$$
\text { IDR }=(\text { ISD + IPI + IE + IA) } / 4 .
$$

Por fim, no que tange aos dados agregados do PRONAF, foram utilizados os dados disponíveis na Plataforma de Gestão de Indicadores do Ministério do Planejamento (2012). Ressalta-se que estes são os dados mais recentes disponíveis e que não mais se encontram disponíveis os dados desagregados por modalidade de recurso. Insta informar que todas as 'variáveis' contidas no quadro 02 foram padronizadas ${ }^{5}$.

\section{Caracterização dos municípios mineiros a partir do IDR}

Nesta parte do trabalho foram caracterizados os municípios mineiros em termos do seu desenvolvimento rural (por meio do IDR) e a distribuição destes municípios pelas diferentes regiões do Estado de Minas Gerais, perfazendo os 853 municípios mineiros. O Indicador de Desenvolvimento Rural foi obtido usando os "subindicadores" já descritos na seção precedente. Os valores do IDR variam no intervalo de 0 a 1. Quanto mais próximo de 1, maior o nível de desenvolvimento do município. Seguindo a proposta de Silva (2006), foi proposta uma classificação do IDR em intervalos, com o intuito de depurar em mais estratos as características em termos de desenvolvimento rural de cada município. Para tanto, o IDR foi dividido em quatro categorias: alto, moderado, baixo e muito baixo, o que pode ser visto no Quadro 03.

Quadro 03 - Limite de valores e classificação do IDR

\begin{tabular}{|c|c|c|c|}
\hline $\begin{array}{c}\text { Total de } \\
\text { Municípios }\end{array}$ & $\begin{array}{c}\text { Classificação dos } \\
\text { Intervalos }\end{array}$ & $\begin{array}{c}\text { Intervalos de } \\
\text { IDR }\end{array}$ & $\begin{array}{c}\text { Quantidade de } \\
\text { Municípios por } \\
\text { Intervalo }\end{array}$ \\
\hline \multirow{3}{*}{853} & Alto & Acima de 0,5 & 21 \\
\cline { 2 - 4 } & Moderado & Entre 0,4 e 0,5 & 395 \\
\cline { 2 - 4 } & Baixo & Entre 0,3 e 0,4 & 376 \\
\cline { 2 - 4 } & Muito Baixo & Abaixo de 0,3 & 61 \\
\hline
\end{tabular}

Fonte: Tabulação própria, a partir dos dados gerados. 
Como se pode perceber, a maioria dos municípios mineiros se enquadra nos intervalos correspondentes às categorias "Moderado" e "Baixo" de desenvolvimento rural. Enquanto isso, apenas 21 municípios obtiveram IDR superior a 0,5.

Figura 01 - IDR por município no Estado de Minas Gerais

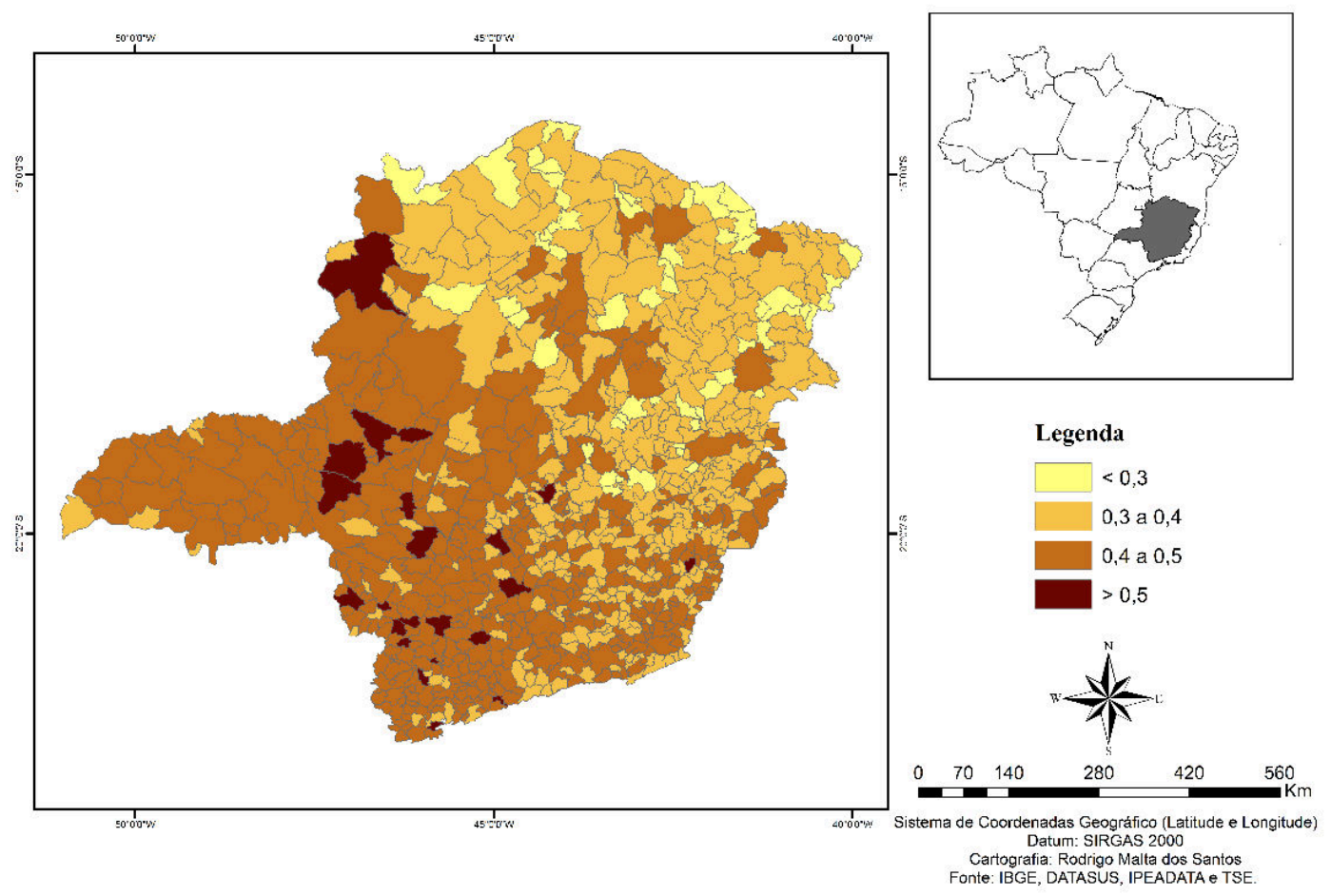

Fonte: Elaboração própria, a partir dos dados do Censo Demográfico (2010); Censo Agropecuário (2006); IPEADATA (2015); Datasus (2015); TSE (2015); Atlas de Desenvolvimento Humano no Brasil (2013).

A Figura 01 reflete como esses municípios se espalham pelo território mineiro. Dos 21 municípios que possuem IDR considerado alto, nenhum deles se localiza nas regiões Norte, Vale do Jequitinhonha e Mucuri do estado de Minas. Essas regiões são reconhecidas por serem áreas menos desenvolvidas e com uma agricultura familiar pouco integrada a economia.

De acordo com Araújo (2014, p. 57), a região Norte do estado tem indicadores econômicos semelhantes aos da Região Nordeste, sendo que o desenvolvimento da economia baseia-se na agricultura de subsistência (em especial, nos cultivos de arroz, feijão, mandioca, milho, cana de açúcar, algodão e extração de borracha). Por outro lado, as regiões do Alto Parnaíba; Noroeste, Oeste e Sul de Minas; Campo das Vertentes e Zona da Mata concentram todos os municípios com IDR Alto. Essas regiões de Minas Gerais são conhecidas por terem economias locais mais dinâmicas e possuírem uma 
agricultura familiar que se diferencia das regiões Norte/ Nordeste do estado, já que há uma inserção maior na rede de negócios local e às cadeias de comercialização. As regiões citadas não possuem nenhum município com IDR Muito Baixo, o que denota um padrão de desenvolvimento rural relativamente mais homogêneo. O Norte de Minas Gerais, Vale do Jequitinhonha, Vale do Mucuri e Vale do Rio Doce concentram a maior parte das cidades com IDR Muito Baixo.

Fica evidente pela Figura 01 que não há nenhum município da região do Triângulo Mineiro, região reconhecida nacionalmente como grande produtora agrícola, na classificação mais alta do Indicador de Desenvolvimento Rural. Isso pode ser explicado por dois fatores: a) o peso da agricultura familiar na composição do IDR sendo que na região do Triângulo predominam uma estrutura fundiária e atividades agropecuárias mais voltadas para a agricultura patronal, principalmente de commodities agropecuárias $^{6}$; b) a importância da agricultura orgânica para a formação do indicador. Isso se deve, segundo os dados do Censo Agropecuário (2006), ao fato de que a agricultura monocultora é predominante no Triângulo Mineiro, com intenso uso de agrotóxicos e mecanização. Dessa forma, os municípios dessa região não atingiram os níveis mais altos do IDR. Contudo, é importante ressaltar que quase a totalidade dos municípios do Triângulo obtiveram IDR Moderado.

\section{Análise da distribuição dos recursos do PRONAF em Minas Gerais frente ao desenvolvimento rural dos seus municípios}

Conforme já foi retratado, o volume de recursos do PRONAF aumentou significativamente nos últimos anos, inclusive para o estado de Minas Gerais. Diversas novas modalidades foram criadas e mais contratos foram assinados, permitindo que o PRONAF atingisse um maior número de famílias, em localidades que antes não eram alcançadas pelo programa.

Contudo, o PRONAF ainda continua destinando mais crédito para os municípios economicamente mais dinâmicos, hipótese que já havia sido testada por Silva (2006), para o PRONAF CRÉDITO, a partir de uma análise dos enquadramentos de agricultores beneficiados pelo Programa. Por este estudo foi constatado que boa parte de municípios do Nordeste brasileiro, com grande participação dos beneficiários nos enquadramentos de mais baixa renda, apresentaram IDR "Muito Baixo" e ainda não tinham acesso aos 
recursos. Em contrapartida, uma gama de municípios enquadrados como IDR "Alto" fora contemplada. De acordo com este trabalho, tal dinâmica pode estar relacionada à dificuldade dos agricultores nos municípios menos desenvolvidos organizarem-se, ter acesso à assistência técnica e ao sistema bancário convencional (via pela qual o crédito é liberado).

De que qualquer forma, seria esperado que a maior concentração de recursos estivesse voltada para os municípios cujos agricultores estivessem mais alijados das políticas públicas e cujo nível de desenvolvimento rural fossem classificados como "Baixo" e "Médio", e não naqueles municípios enquadrados como de IDR "Alto"(Silva, 2006, p. 180). Contrapondo as constatações observadas no estudo indicado com os dados das Tabelas 01 e 02, verifica-se que mesmo tendo avançado em termos do aumento das dotações e das liberações de recursos nos últimos anos, o PRONAF ainda se destina, em sua maior parte para os agricultores dos municípios que apresentam melhores indicadores sociais e maior IDR.

Tabela 01 - Os 10 municípios com maiores IDR de Minas Gerais

\begin{tabular}{|c|c|c|c|c|}
\hline Municípios & $\begin{array}{c}\text { PIB AGRO } \\
\text { (RS 1000,00) }\end{array}$ & $\begin{array}{c}\text { Montante } \\
\text { PRONAF (RS } \\
\text { 1000,00) }\end{array}$ & IDHM & IDR \\
\hline Patrocínio & $168.668,95$ & $18.526,45$ & 0,729 & 0,570 \\
\hline Patos de Minas & $105.446,89$ & $11.986,38$ & 0,765 & 0,550 \\
\hline Perdizes & $127.668,93$ & $3.337,12$ & 0,723 & 0,550 \\
\hline $\begin{array}{l}\text { Campos Gerais } \\
\text { Carmo da }\end{array}$ & $56.327,66$ & $8.283,24$ & 0,682 & 0,526 \\
\hline Cachoeira & $29.886,65$ & $1.822,86$ & 0,655 & 0,519 \\
\hline Santa Margarida & $26.833,66$ & $3.033,11$ & 0,61 & 0,519 \\
\hline Campos Altos & $53.211,48$ & $2.425,44$ & 0,702 & 0,517 \\
\hline $\begin{array}{l}\text { Itanhandu } \\
\text { Bom Jesus da }\end{array}$ & $45.050,41$ & 952,26 & 0,739 & 0,514 \\
\hline Penha & $15.416,95$ & $4.170,15$ & 0,735 & 0,513 \\
\hline Divinópolis & $35.329,31$ & $2.343,98$ & 0,764 & 0,510 \\
\hline
\end{tabular}

Ao se contrastar os 10 municípios mineiros com maior IDR vis a vis os 10 outros com os menores valores para este do indicador pode-se observar distorção na liberação o de recursos. Dentre os municípios, os que mais receberam recursos do Programa, há maior diversificação econômica, sendo que somente em dois deles foi verificado maior 
participação do PIB agropecuário (Perdizes e Itanhandu). Nos demais, a participação do setor de serviços perfaz a maior parte do PIB, seguido pela indústria (IBGE, 2014), apesar de que em boa parte destes (como exemplo, Patrocínio, Patos de Minas, Campos Gerais), o setor de serviços está muito correlacionado com a agroindústria ${ }^{7}$. Nota-se que apenas Itanhandu recebeu menos de 1 milhão de reais para financiamentos em 2012.

Em contrapartida, entre os 10 menores indicadores de desenvolvimento rural, apenas um município recebeu acima de 1 milhão de reais em financiamento: Poté, localidade que tem o maior peso do PIB voltado para o setor de serviços (72\%) e uma participação da agropecuária relativamente baixa (cerca de 11\%).

Tabela 02 - Os 10 municípios com menores IDR de Minas Gerais

\begin{tabular}{lcccc}
\hline \multicolumn{1}{c}{ Municípios } & $\begin{array}{c}\text { PIB AGRO } \\
(\mathbf{R} \mathbf{1 0 0 0 , 0 0 )}\end{array}$ & $\begin{array}{c}\text { Montante } \\
\text { PRONAF (RS } \\
\mathbf{1 0 0 0 , 0 0 )}\end{array}$ & IDHM & IDR \\
\hline Poté & $4.763,46$ & $2.401,80$ & 0,624 & 0,260 \\
Bertópolis & $3.480,64$ & 778,84 & 0,594 & 0,256 \\
São João das Missões & $2.088,71$ & 943,23 & 0,529 & 0,253 \\
Catuji & $1.891,71$ & 554,67 & 0,54 & 0,251 \\
Cristália & $5.433,27$ & 819,44 & 0,583 & 0,249 \\
Ninheira & $4.898,69$ & 329,00 & 0,556 & 0,247 \\
Congonhas do Norte & $1.475,74$ & 771,47 & 0,568 & 0,247 \\
Vargem Grande do Rio & & & & \\
Pardo & $3.166,14$ & 488,10 & 0,634 & 0,241 \\
Serra Azul de Minas & $1.277,30$ & 230,07 & 0,557 & 0,225 \\
Cachoeira de Pajeú & $4.099,67$ & 572,06 & 0,578 & 0,216 \\
\hline
\end{tabular}

Fonte: elaboração própria a partir dos dados disponibilizados na plataforma virtual do IBGE, IPEADATA, Atlas do Desenvolvimento Humano do Brasil e Plataforma de Gestão de Indicadores do Ministério do Planejamento.

A explicação para um alto montante de recursos do PRONAF estaria relacionada à adesão ao Programa de Comercialização Coletiva de Avicultura Familiar, em 2010. A proposta visa principalmente organizar a compra e a venda coletiva das aves com vistas a obterem melhor preço. O mesmo funciona para a comercialização, feita em conjunto com o Programa de Aquisição de Alimentos (PAA) do Governo Federal, cuja venda de $50 \%$ da produção do grupo era adquirida pela Companhia Nacional de Abastecimento CONAB (EMATER - MG, 2015).

Em municípios como Bertópolis, por exemplo, predominam pequenas propriedades de autossubsistência, com pequena produção de corte e engorda de gado ${ }^{8}$, O município de Serra Azul de Minas foi um dos que apresentaram menor índice de 
desenvolvimento rural e está entre o que menos recebeu recursos do PRONAF. Parte da sua produção familiar está voltada para a produção de queijos ${ }^{9}$.

Ao observarmos as Tabelas 02 e 03 podemos notar também que existe uma consonância entre o IDR e o Índice de Desenvolvimento Humano Municipal (IDHM). Entre os municípios mineiros com maior IDR apenas três possuem IDHM inferior a 0,7; naqueles com os menores IDR, apenas dois deles ultrapassaram a marca de 0,6 no IDHM. As Tabelas 02 e 03 e os Quadros A e B, que estão no Anexo I, corroboram com o que foi afirmado por Silva (2006). Dos 25 municípios mineiros que receberam as melhores avaliações no IDR, cinco deles estão entre os municípios que mais receberam verbas do PRONAF. Nenhum dos 25 municípios com menor IDR está entre os que mais receberam verbas do PRONAF. Nesse sentido, a questão da territorialidade é importante para se entender a distribuição do montante de financiamento do PRONAF. Aqueles que mais recebem recursos do programa se localizam nas regiões em que a agricultura familiar é mais integrada à economia local e regional. Cidades como Patrocínio e Patos de Minas que se localizam na região do Alto Parnaíba são exemplos disso. Patos de Minas é conhecida por ser a capital nacional do milho, mas também soja, café, mandioca e feijão.

De acordo com informações do site da Prefeitura Municipal e da plataforma virtual IBGE Cidades, há um grande dinamismo na agricultura da cidade devido também ao Centro Integrado de Abastecimento (Ceasa Regional), que permitem que agricultores familiares (em especial, os hortifrutigranjeiros) comercializem sua produção de maneira direta, sem intermediários. Patrocínio, do mesmo modo, é uma das cidades que mais recebe recursos do PRONAF, tendo sua agricultura voltada para a produção de café, milho, soja feijão, algodão e arroz e a produção de leite que é escoada, em sua maior parte, para Belo Horizonte.

A Figura 02 mostra uma situação que corrobora com o que foi citado anteriormente. Na maior parte das regiões de Minas Gerais nas quais a Agricultura Familiar não é tão dinâmica (como em Patrocínio e Patos de Minas), o montante de financiamento do PRONAF é significantemente menor. Principalmente nas regiões Norte, do Vale do Jequitinhonha, Vale do Mucuri e Rio Doce, poucos foram os municípios que receberam mais de 2,5 milhões de reais em empréstimos deste 
Programa. Ainda, as Figuras 01 e 02 possuem alguns pontos em comum que devem ser ressaltados.

Figura 02 - Montante de Financiamento do PRONAF por município no Estado de Minas Gerais

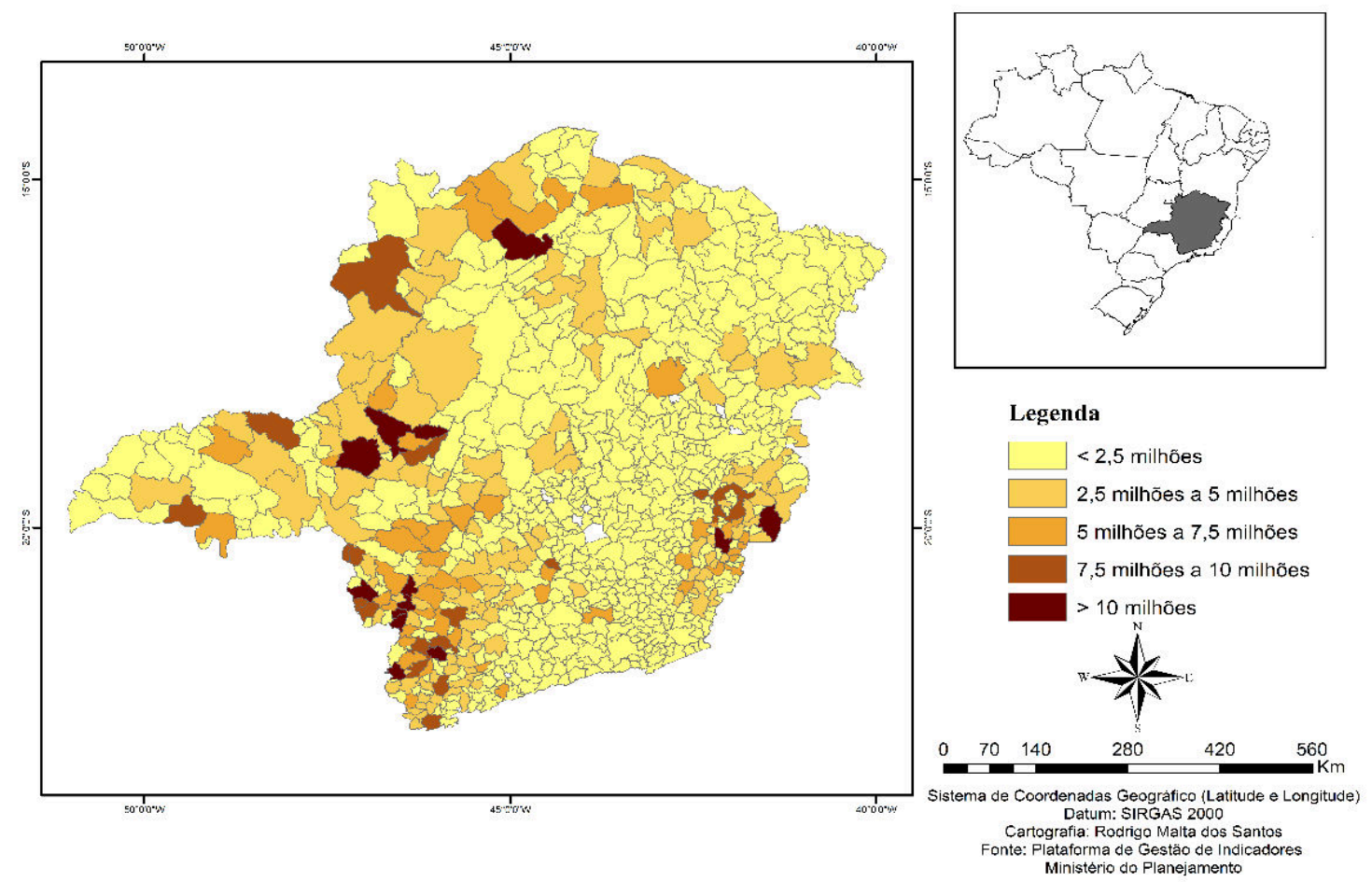

Fonte: elaboração própria, a partir dos dados da Plataforma de Gestão de Indicadores do Ministério do Planejamento (2012).

Os municípios classificados com o IDR Baixo ou Muito Baixo na Figura 01 coincidem amplamente com os municípios que receberam menos verbas via financiamento do PRONAF, principalmente nas regiões Norte, do Vale do Jequitinhonha, Vale do Mucuri e Rio Doce. Da mesma forma, a Região do Alto Parnaíba e Sul de Minas concentram os municípios com os maiores níveis de desenvolvimento rural. Esses municípios foram também os que mais receberam verbas do PRONAF em 2012 de acordo com a Plataforma de Gestão de Indicadores do Ministério do Planejamento.

Com isso, corrobora-se a hipótese de que a lógica de concentração de recursos do PRONAF continua concentradora naqueles municípios com melhores indicadores econômicos, sociais, institucionais e ambientais. A despeito da criação de novas modalidades como tentativa de incorporar outros públicos - alvos mais marginalizados, 
o programa continua tendo uma atuação mais efetiva nos municípios economicamente mais integrados.

\section{CONSIDERAÇÕES FINAIS}

Esse trabalho se propôs a atualizar um debate já existente em termos de se pensar qual o público alvo que deveria ser potencializado por um instrumento de política pública, em especial, quando se trata de agricultores familiares. Daí a importância de se confrontar a lógica de distribuição dos recursos do PRONAF, no âmbito dos municípios mineiros, com o seu nível de desenvolvimento rural. Para isso, partiu-se de uma adaptação do Indicador de Desenvolvimento Rural (IDR) baseado no indicador desenvolvido por Kageyama (2004) e Silva (2006).

Por meio deste indicador, os 853 municípios mineiros foram classificados em um ranking que avalia aspectos muito mais profundos que apenas a produção agrícola de cada municipalidade: contemplando também outras dimensões importantes: institucionais, ambientais, econômica, demográficas e sociais. A análise dos quatro "sub-indicadores" componentes do IDR permitiu que a diversidade do Estado de Minas Gerais viesse à tona. As regiões do estado apresentam diferentes graus de desenvolvimento entre elas, e demonstraram também diferentes graus de desenvolvimento entre seus municípios.

Desde a data da criação do PRONAF até os dias de hoje, os municípios mineiros se desenvolveram muito e deram importante passo para superar problemas graves como a subnutrição, analfabetismo, acesso à água, pobreza extrema, desemprego - toda essa evolução pode ser acompanhada pela plataforma virtual do Atlas do Desenvolvimento Humano no Brasil (2013). O PRONAF, portanto, torna-se um aliado a diversas outras políticas públicas, e tem sido um fator importante para promover o desenvolvimento social para essas municipalidades. No entanto, o desenvolvimento rural não ocorre na mesma intensidade em todos os municípios do Estado de Minas Gerais, até pelas suas distintas características estruturais. O Programa, então, ainda peca pela sua lógica concentradora, ao contemplar agricultores mais integrados ao mercado e municipalidades mais desenvolvidas em termos de desenvolvimento rural.

A importância do IDR se revela nesse aspecto: determinar quais munícipios carecem de maior atenção dos entes públicos na definição e implementação de 
estratégias de desenvolvimento local, principalmente em regiões mais marginalizadas, tais como os das regiões Norte e Nordeste do estado que necessitam de melhor aperfeiçoamento das políticas públicas. O PRONAF, pela sua capilaridade e abrangência, tem um grande papel neste ponto, enquanto principal instrumento de política pública voltado para a agricultura familiar.

No entanto, a importância do Programa não minimiza a crítica que se faz à sua institucionalidade. Ainda falta conseguir apoiar os municípios que são mais carentes de políticas públicas. Faz-se necessário aprimorar o desenho deste Programa, de forma que os municípios com menores índices de IDR acessem estes recursos. Conforme constatado neste estudo e em consonância com Silva (2006), os municípios de menor nível de desenvolvimento rural foram aqueles que menos receberam financiamento deste programa. A explicação para tal persistência vai ao encontro com hipóteses que já vem sendo difundidas nestes últimos anos por Silva (2006); Corrêa e Silva (2007); Guanziroli (2007); Silveira e Valadares (2014), quais sejam, as liberações dos recursos do PRONAF continuam seguindo uma lógica concentradora, mercadológica e bancária. Ao se financiar preferencialmente os agricultores que já possuem garantias de pagamento e/ou estão estruturados, operando com uma lógica bancária, o PRONAF tem o seu poder de levar crédito aos agricultores familiares mais alijados das políticas públicas e menos integrados ao mercado limitado.

Além disso, essa lógica estimularia pouco o direcionamento de recursos para as regiões menos favorecidas. Dessa forma, a caracterização dos municípios mineiros de acordo com o grau de desenvolvimento rural - feita pelo IDR se revela importante, pois indica quais munícipios carecem de maiores estímulos via políticas públicas por parte do Estado. Em Minas Gerais, as regiões Norte e Nordeste, em especial, necessitam de mais empenho do poder público para impulsionar um maior desenvolvimento socioeconômico nestas regiões.

\section{Notas}

\footnotetext{
${ }^{1}$ Para um amplo detalhamento sobre estas mudanças, ver Schneider e Marques (2004).

${ }^{2}$ Dentre as subcategorias da modalidade de Investimento, destacam-se: PRONAF Investimento 'Mais Alimento'; 'Agroindústria'; 'Floresta'; 'Semi-Árido'; 'Mulher, Jovem', 'Agroecologia' e Investimento em 'Energia Renovável e Sustentabilidade Ambiental' (Pronaf Eco).

De acordo com o Banco Central do Brasil, as modalidades de créditos, independentemente da classificação dos beneficiários a que se destinam, devem objetivar, sempre que possível, o
} 
desenvolvimento do estabelecimento rural como um todo. Mais esclarecimentos podem ser obtidos no endereço virtual: http://www.bcb.gov.br/pre/bc_atende/port/PRONAF.asp\#9

${ }^{3}$ De acordo com o Censo Demográfico de 2010 (IBGE).

${ }^{4}$ Tendo em vista a inexistência de dados secundários voltados exclusivamente para a Agricultura Familiar em Minas Gerais, foi considerado o PIB agropecuário agregado (com o somatório da agricultura patronal e a familiar).

${ }^{5}$ A padronização consiste em fazer uma transformação algébrica para que o índice varie no intervalo de zero a um. Essa transformação é o quociente (valor da variável - mínimo)/(máximo - mínimo).

${ }^{6}$ A participação da agricultura familiar nesta região, com relação ao total de agricultores familiares de Minas Gerais corresponde a 9\% (Governo de Minas, 2014)

${ }^{7}$ IBGE (2014) Instituto Brasileiro de Geografia e Estatística/ Cidades. Disponível no site: http://cidades.ibge.gov.br/xtras/uf.php?lang=\&coduf=31\&search=minas-gerais. Acesso em novembro de 2015.

8 De acordo com o site institucional da Prefeitura do Município (http://www.bertopolis.mg.gov.br/crbst_7.html). Acesso em novembro de 2015.

${ }^{9}$ Segundo a EMATER MG, junto a outros municípios, forma a região produtora do "Serro": Alvorada de Minas, Conceição do Mato Dentro, Dom Joaquim, Materlândia, Paulistas, Rio Vermelho, Sabinópolis, Santo António do Itambé, Serra Azul de Minas, Serro.

\section{REFERÊNCIAS}

ARAÚJO, C. A. L. Desenvolvimento rural: uma análise de indicadores populacionais, sociais, econômicos e ambientais. 2014. 91 f. Dissertação (Mestrado em Desenvolvimento Social) - Universidade Estadual de Montes Claros, 2014.

ATLAS DO DESENVOLVIMENTO HUMANO NO BRASIL. Índice de Desenvolvimento Humano Municipal. Disponível em: http://atlasbrasil.org.br/2013/. Acessado em: janeiro, 2015.

BANCO CENTRAL DO BRASIL. FAQ - Programa Nacional de Fortalecimento da Agricultura Familiar - PRONAF. Disponível em:

http://www.bcb.gov.br/pre/bc_atende/port/PRONAF.asp\#11 acesso em 23 de outubro de 2015.

BANCO CENTRAL DO BRASIL. Resolução nº 2101 Crédito Rural. Programa de Valorização da Pequena Produção Rural (PROVAPE) - Safra de Verão 1994/95. Disponível em:

http://www.bcb.gov.br/pre/normativos/busca/downloadNormativo.asp?arquivo=/Lists/N ormativos/Attachments/43273/Res_2101_v1_O.pdf acesso em 23 de outubro de 2015.

BELIK, W. A Heterogeneidade e suas Implicações para as Políticas Públicas no Rural Brasileiro. Revista de Economia e Sociologia Rural, 53(1), 9-30, 2015.

CORRÊA, V.P. ; SILVA, F. F. . Análise das liberações recentes de recursos do PRONAF ? uma mudança na lógica de distribuição?. Revista Econômica do Nordeste, v. 38, p. 26-46, 2007.

FAO/INCRA. Projeto de Cooperação Técnica - Novo retrato da agricultura familiar: o Brasil redescoberto: Brasília, INCRA:2000. 
FAO/INCRA. Perfil da Agricultura Familiar no Brasil. Dossiê estatístico. Projeto UFT/BRA/036/BRA. Brasília: 1996.

GOVERNO DO ESTADO DE MINAS GERAIS - EMATER MG - Perfil da

Agricultura Familiar de Minas Gerais. Documento de trabalho. 2014. Disponível em: http://www.agricultura.mg.gov.br/images/files/Perfil\%20da\%20Agricultura\%20Familia r\%20v2.pdf. Acesso em julho de 2015.

GUANZIROLI, C. E. PRONAF dez anos depois: resultados e perspectivas para o desenvolvimento rural. RER - Revista de Economia Rural, Rio de Janeiro, v. 45, n.2, p. 301-328, abr-jun 2007.

INSTITUTO BRASILEIRO DE GEOGRAFIA E ESTATÍSTICA (IBGE); INSTITUTO BRASILEIRO DE GEOGRAFIA E ESTATÍSTICA (IBGE). Censo Demográfico 2010Resultados gerais da amostra.

INSTITUTO BRASILEIRO DE GEOGRAFIA E ESTATÍSTICA. Comentários: Brasil agrário retratado pelo Censo Agropecuário 2006. Notas de esclarecimento. Disponível em:

http://www.ibge.gov.br/home/estatistica/economia/agropecuaria/censoagro/brasil_2006/ comentarios.pdf acesso em 20 maio 2015.

INSTITUTO DE PESQUISA ECONÔMICA APLICADA (IPEA). IPEADATA.

Disponível em: http://ipeadata.gov.br/. Acessado em janeiro de 2015.

KAGEYAMA, A. "Desenvolvimento Rural: conceito e um exemplo de medida". Anais do XLIII Congresso da SOBER Cuiabá (MT). 2004.

MATTEI, L PRONAF 10 anos: mapa da produção acadêmica - Brasília: Ministério do Desenvolvimento Agrário, 2006 (Núcleo de Estudos Agrários e Desenvolvimento Rural - NEAD, Estudos, v.12).

MINISTÉRIO DA SAÚDE. Departamento de Informática do Sistema Único de Saúde (DATASUS). Indicadores e dados básicos. Disponível em: http://www.datasus.gov.br. Acesso em outubro de 2015.

MINISTÉRIO DO PLANEJAMENTO. Plataforma de Gestão de Indicadores (2012). Disponível em: http://www.i3gov.planejamento.gov.br. Acesso em outubro de 2015.

PRESIDÊNCIA DA REPÚBLICA SUBCHEFIA PARA ASSUNTOS JURÍDICOS. Decreto n.1.946 de 28 de junho de 1996 - Cria o Programa Nacional de Fortalecimento da Agricultura Familiar - PRONAF, e dá outras providências. Disponível em: http://www.planalto.gov.br/ccivil_03/decreto/D1946.htm acesso em 20 maio 2015.

SCHNEIDER, S. CASSOL, A. A agricultura familiar no Brasil. Serie Documentos de Trabajo. Santiago, Chile: Grupo de Trabajo: Desarrollo con Cohesión Territorial (Programa Cohesión Territorial para el Desarrollo), 2013. 


\section{SCHNEIDER. S. e MARQUES, P.E.M (Orgs) Políticas Públicas e Participação}

Social no Brasil Rural, Porto Alegre, ED. UFRGS, 2004.

SILVA, F. F. Distribuição de crédito para agricultura familiar: um estudo do PRONAF a partir de um indicador de desenvolvimento rural. 250 f. Dissertação (Mestrado em Ciências Econômicas), Universidade Federal de Uberlândia, 2006.

SILVEIRA, F. G.; VALADARES, A. A. Evolução Recente do PRONAF-Crédito: 1999 a 2013. In: 52 ${ }^{\circ}$ Congresso da SOBER, 2014, Goiânia. Anais...Disponível em:

http://itarget.com.br/newclients/sober.org.br/2014/52 congresso/pdf/sessao2.pdf. Acesso: maio de 2015

STEGE, A. L.; PARRÉ, J. L. Fatores que determinam o desenvolvimento rural nas microrregiões do Brasil. Confins [online] Revista Franco-Brasileira de Geografia, n.19, 2013. Disponível em: http://confins.revues.org/8640 . Acesso: Dezembro 2015.

TRIBUNAL SUPERIOR ELEITORAL (TSE). Repositório de dados eleitorais.

Disponível em:

http://www.tse.jus.br/eleicoes/estatisticas/repositoriodedadoseleitorais,2015.Acesso: maio 2015.

\section{ANEXO I}

\begin{tabular}{|l|c|}
\hline $\begin{array}{c}\text { Municípios Mineiros } \\
\text { com maior IDR }\end{array}$ & $\begin{array}{c}\text { IDR } \\
\text { (ISD+IPI+IE+IA) }\end{array}$ \\
\hline 1. Patrocínio & 0,570 \\
\hline 2. Patos de Minas & 0,550 \\
\hline 3. Perdizes & 0,550 \\
\hline 4. Campos Gerais & 0,526 \\
\hline 5. Carmo da & \\
\hline Cachoeira & 0,519 \\
\hline 6. Santa Margarida & 0,519 \\
\hline 7. Campos Altos & 0,517 \\
\hline 8. Itanhandu & 0,514 \\
\hline 9. Bom Jesus da & 0,513 \\
\hline Penha & 0,510 \\
\hline 10. Divinópolis & 0,508 \\
\hline 11. Bambuí & 0,508 \\
\hline 12. Gonçalves & 0,508 \\
\hline 13. São Sebastião \\
do Paraíso
\end{tabular}

\begin{tabular}{|c|c|}
\hline $\begin{array}{l}\text { Municípios Mineiros } \\
\text { com maior repasse de } \\
\text { PRONAF }\end{array}$ & $\begin{array}{l}\text { Montante } \\
\text { PRONAF } \\
\text { (RS 1000) }\end{array}$ \\
\hline 1. Nova Resende & $22.080,71$ \\
\hline 2. Patrocínio & $18.526,45$ \\
\hline 3. Alpinópolis & $14.362,01$ \\
\hline 4. Andradas & $12.979,95$ \\
\hline 5. Mutum & $12.673,78$ \\
\hline 6. Poço Fundo & $12.209,59$ \\
\hline 7. Patos de Minas & $11.986,39$ \\
\hline $\begin{array}{l}\text { 8. São Sebastião do } \\
\text { Paraíso }\end{array}$ & $11.894,75$ \\
\hline 9. Manhuaçu & $11.599,34$ \\
\hline 10. Juruaia & $10.979,33$ \\
\hline 11. Muzambinho & $10.412,86$ \\
\hline 12. São Francisco & $10.379,78$ \\
\hline $\begin{array}{l}\text { 13. Santa Rita de } \\
\text { Caldas }\end{array}$ & $9.891,54$ \\
\hline 14. Araguari & $9.839,7$ \\
\hline 15. Camanducaia & $9.402,71$ \\
\hline
\end{tabular}




\begin{tabular}{|c|c|c|c|}
\hline 16. Sete Lagoas & 0,504 & 16. Ibiraci & $9.402,02$ \\
\hline 17. Monte Belo & 0,504 & 17. Caratinga & $9.320,18$ \\
\hline 18. Alterosa & 0,503 & 18. Unaí & $9.190,9$ \\
\hline 19. Oliveira & 0,503 & 19. Itamogi & $8.640,32$ \\
\hline $\begin{array}{l}\text { 20. Espírito Santo } \\
\text { do Dourado }\end{array}$ & 0,503 & 20. Inhapim & $8.447,63$ \\
\hline 21. Unaí & 0,501 & 21. Claraval & $8.303,33$ \\
\hline 22. Três Pontas & 0,500 & 22. Campos Gerais & $8.283,24$ \\
\hline 23. Passos & 0,500 & $\begin{array}{l}\text { 23. Monte Santo de } \\
\text { Minas }\end{array}$ & $8.249,93$ \\
\hline 24. Tupaciguara & 0,499 & 24. Campestre & $8.230,13$ \\
\hline 25. Nova Resende & 0,498 & 25. Itapagipe & $8.184,88$ \\
\hline
\end{tabular}

Fonte: elaboração própria a partir dos dados disponibilizados na plataforma virtual do IBGE, IPEADATA, Atlas do Desenvolvimento Humano do Brasil e Plataforma de Gestão de Indicadores do Ministério do Planejamento.

Recebido em 23/06/2018.

Aceito para publicação em 11/02/2019. 